\title{
Research on Urban Environmental Protection Measures-Takeing Shanghai as an Example
}

\author{
Litong Xue,
}

${ }^{1}$ Calvary Day School, Winston-Salem, NC 27104, the U.S.

*Corresponding author.Email: cds@calvaryday.school

\begin{abstract}
With the social and economic development of people's living standard has been improved, but also caused serious damage to the ecological environment. The protection of the ecological environment has become particularly prominent. Therefore, this paper takes Shanghai as an example to study a series of protective measures taken by Shanghai and their effectiveness. It can be concluded that through measures such as strengthening environmental governance and ecological restoration, implementing environmental infrastructure construction, promoting the integration of regional environmental governance, improving the modern environmental protection system, and vigorously advocating green and low-carbon development, the environmental quality of Shanghai has been significantly improved. Especially through the strengthening of environmental governance and ecological restoration, the concentration of major pollutants in the city has gradually decreased, and resource-saving and environmentally friendly products and technologies have been continuously developed, formed the industrial system of low-carbon cycle, provides a strong reference for the environmental protection measures other cities.
\end{abstract}

Keywords: urban construction, environmental protection, Yangtze River Delta region, environmental law enforcement

\section{INTRODUCTION}

Nature is an important environment for human survival. With the acceleration of urbanization and modernization of the continuous development of human activities increasingly prominent problems of the destruction of the ecological environment, social stability and economic development had a serious impact, How to regulate the relationship between urban development and the ecological environment has become a hot issue in today's general interest. The report of the 19th National Congress of the Communist Party of China, insist on the harmonious coexistence of man and nature, we must establish and practice the concept that green water and green mountains are golden mountains and silver mountains, and adhere to the basic national policy of saving resources and protecting the environment. Therefore, it is imperative to do a good job of environmental protection in urban and rural construction. In order to promote the construction of ecological civilization, and promote green development and green living, urban development planning and environmental protection measures need to go in, we must be reasonable to promote urban development from the perspective of sustainable development[1]. This article mainly studies the environmental protection measures in Shanghai and their achievements. By combing through a series of environmental protection policies and measures adopted by Shanghai in recent years, based on the current situation of Shanghai's environmental quality development, analysis of the current environmental protection achievements in terms of technical level, infrastructure, regional development, legislative system and environmental awareness, etc., Summarize the beneficial measures for environmental protection in Shanghai, promote the sustainable development of the city, and create a better urban living environment.

\section{SHANGHAI ENVIRONMENTAL PROTECTION MEASURES}

The process of urbanization in Shanghai has been accelerating. While improving people's material level, the lack of attention to environmental protection has broken the balance between human society and the natural environment. The environmental pollution problem has become increasingly severe, causing drinking water pollution, smog, and haze. environmental 
pollution light pollution, urban noise, to the health of the people adversely affected [2]. Rely on the correct policy guidance, after all positive prevention and to strengthen management, industrial pollution to the 1990 Shanghai basically under control, slowing the deterioration of environmental quality, environmental quality has improved in some areas. However, the acid rain problem was still serious at that time, the water quality of some river sections had not been fundamentally improved, the domestic sewage treatment facilities were not compatible with the urban development, and the development of urbanization was restricted. In recent years, with the emphasis on the ecological environment, to "Thirteen Five" late, the quality of the city's ecological environment has been significantly improved, and gradually form of the modern environmental governance system.

\subsection{Strengthen environmental governance and ecological restoration}

The Shanghai government strengthens support for green technological innovation in key areas, encourages independent innovation of key environmental protection technology products, and vigorously develops intelligent monitoring technology and equipment. Carry out thirdparty service pilots in industrial parks, streets and key areas, strengthen water source safety, and strengthen comprehensive water environment management and ecological restoration.

In order to fight the battle to defend the blue sky, Shanghai completely abolished loose coal and strictly controlled the total amount of coal consumption, thus speeding up the implementation of clean energy substitution and deepening the prevention and control of dust pollution. At the same time, Shanghai strengthened the monitoring and evaluation of soil environmental quality, strengthened soil control and safe use of agricultural land, and continued to promote site pollution control. With "reduction, harmlessness, and resource utilization" as the core, the Shanghai government has accelerated the promotion of domestic waste classification and comprehensive utilization of resources, strengthened the comprehensive utilization of general industrial solid waste, improved the level of recycling and utilization of renewable resources, and realized the efficient recycling of various resources use.

In addition, the Shanghai government has also focused on "reduction, harmlessness, and resource utilization" to accelerate the promotion of domestic waste classification and comprehensive utilization of resources, strengthen the comprehensive utilization of general industrial solid waste, and improve the level of recycling and utilization of renewable resources.

\subsection{Implement environmental infrastructure construction}

In order to improve the construction of water environment infrastructure, Shanghai comprehensively implemented the upgrading and renovation of sewage treatment plants, strengthened the construction of sewage pipe networks in densely populated areas such as the old city and suburban areas, and coordinated the renovation and reconstruction of key areas, and strengthened the efforts to intercept sewage pipes, and further Increase the operating load rate of sewage treatment plants. In order to improve the impact of odors on the surrounding environment in the sewage treatment process, Shanghai Bailonggang Sewage Treatment Plant carried out upgrading and transformation, and the deodorization project built is currently the world's largest and highest level of deodorization innovation project for sewage treatment plants. By accelerating the construction of sewage treatment plant sludge treatment facilities, Shanghai has ensured the safe disposal of sewage treatment plant sludge. Shanghai has also simultaneously carried out the treatment of odor in sewage treatment plants, and comprehensively strengthened the treatment of sludge and odor. Shanghai has carried out large-scale inspections of drainage pipelines in urban built-up areas, carried out rainwater pollution renovation in old communities according to local conditions, and focused on promoting pollution control of municipal facilities.

At the same time, Shanghai has also established a sponge city construction technical standard and control system that meets the characteristics of Shanghai, and has steadily promoted the construction of the sponge city.

During the "13th Five-Year Plan" period, Shanghai completed the renovation and upgrading of 31 urban sewage treatment plants and the expansion of 17 sewage treatment plants, with an urban sewage treatment rate reaching about 97\%; and upgrading of rural domestic sewage treatment facilities, the rural domestic sewage treatment rate reached $88 \%$; Increase the domestic waste incineration and wet waste centralized treatment capacity by 17,000 tons/day; build 7 parks with an open forest coverage rate of about $18 \%[3]$.

\subsection{Promote the integration of regional environmental governance}

With the increased awareness of regional cooperation, the Yangtze River Delta region continues to explore and improve the ecological environment cooperation mechanism key areas, and try to carry out regional environmental cooperation activities.

In 2009, the Yangtze River Delta Regional Environmental Cooperation Joint Conference was held for the first time. The environmental protection departments of the "three provinces and one city" are 
responsible for comprehensive management of water pollution in the river basin, joint regional air prevention and control, and emergency treatment of transboundary pollution. In 2013, the State Council required the BeijingTianjin-Hebei, Yangtze River Delta, and Pearl River Delta to establish a regional air pollution prevention and control cooperation mechanism to strengthen joint pollution prevention and control, and required the establishment of a water pollution prevention and joint prevention and joint cooperation mechanism by the end of 2015. Qingpu District, Shanghai, Wujiang District, Suzhou City, Jiangsu Province, and Jiashan County, Jiaxing City, Zhejiang Province, promoted the establishment of a sound cross-border on-site inspection and mutual recognition mechanism for environmental law enforcement, and coordinated and contacted the two districts and one county ecological environment comprehensive law enforcement team. The government speeds up the integration process of ecological environment governance in the Yangtze River Delta through measures such as strengthening the cooperation in environmental law enforcement in the Yangtze River Delta, establishing a policy coordination mechanism, improving the information sharing mechanism, and strengthening the construction of the ecological environment. [4]. Since the 18th National Congress of the Communist Party of China, the capacity of joint prevention and control of the ecological environment in the Yangtze River Delta region has been continuously enhanced, and the quality of the ecological environment has been continuously improved. In 2019, the average concentration of fine particulate matter (PM2.5) in 41 cities decreased by $19.6 \%$ compared with 2015 , and the water quality of 333 surface water sections in the national examination was increased by $11.7 \%$ compared with 2015[5].

\subsection{Improve the modern environmental protection system}

With the advance of the campaign of prevention and control of pollution, Shanghai formed a complete system of environmental protection laws and relevant laws and regulations and environmental standards. Environmental law enforcement has become a powerful weapon to control environmental problems. Shanghai, according to local conditions, to accelerate the improvement and Local Law Construction, started the construction of a modern system of environmental protection work, we have developed a series of local laws and regulations, including the 《Regulations of Shanghai Municipality drinking water source protection 》, 《Shanghai Environmental Protection Ordinance 》 《atmospheric pollution prevention Act of Shanghai 》 and 《Shanghai water management a number of provisions 》. The Shanghai government revised and promulgated the "Shanghai Municipal Environmental Violation Reporting and Reward Measures" to encourage and guide the public to participate in the supervision of environmental violations. While improving laws and regulations, Shanghai's environmental protection law enforcement has continued to increase. Shanghai Municipal Law Enforcement Bureau and comprehensive spot checks on the ecological environment, special inspections and spot checks, and other forms of law enforcement. In this way, a comprehensive, centralized, and comprehensive law enforcement inspection system is formed to solve hot issues in environmental complaints and reports, and to promote environmental solutions to issues in hot areas. In 2019, 57 environmental violations were investigated and dealt with. 31 companies involved in water and solid waste were suspected of environmental violations [6].

\subsection{Advocate the green low-carbon development}

At present, green and low-carbon development has become a global consensus, and livability has also become an important indicator of competitive cities. The government should take corresponding measures to raise the public's awareness of environmental protection, improve the living environment, and optimize the construction of the urban environment [7].

Shanghai has formulated a green development and green life action guide to guide enterprises and individuals to save resources, reduce pollution, and promote the establishment of production and lifestyles that are conducive to environmental protection.

Shanghai promotes green buildings, green travel, and promotes consumption of green products, promotes the creation of energy-saving institutions, green homes, green schools and other key activity areas, improves noise pollution prevention and management systems, and encourages the public to actively practice green and lowcarbon lifestyles. Only by creating a good ecological environment can the green development of the city be realized.

Finally, on the basis of popularizing knowledge and education of ecological civilization in the whole society and improving citizens' awareness of environmental protection, Shanghai has carried out the construction of ecological civilization in the region and the construction of cultural systems to improve the environment [8].

\section{CONCLUSION}

In the process of social development, we must strengthen environmental protection measures, continue to improve environmental quality, promote sustainable urban development, and enable the people to live and work in peace and contentment. This article mainly studies the environmental protection measures in Shanghai and their achievements. Environmental protection measures are strengthening environmental 
governance and ecological restoration, implement environmental infrastructure construction, promote the integration of regional environmental governance, improve the modern environmental protection system, advocate the green low-carbon development

\section{ACKNOWLEDGMENTS}

I am very honored to participate in professor $\mathrm{Li}$ Wenhong's scientific research project, from basic theoretical learning to in-depth research. Due to my lack of professional knowledge, theoretical knowledge is not enough to support my in-depth research, and the alarm bell for making mistakes is often hung, not to mention the psychological burden. In the process of research, it was your patient guidance that taught me how to conduct research in a standardized and correct way. When I do something wrong and feel guilty, you are so timely to correct and encourage. It is because of the hard work and high sense of responsibility like you that I truly feel the charm of environmental science.

\section{REFERENCES}

[1] Zhao Han. Analysis of environmental protection measures in urban and rural construction $[\mathrm{J}]$. Green environmental protection building materials (7): 2 .

[2] Tian Yanfang, Zhou Honghong. Comprehensive evaluation of urban ecological environment quality in Shanghai[J]. Ecological Economy, 37(6): 8.

[3] General Office of the Shanghai Municipal People's Government. The "14th Five-Year Plan" of Shanghai's Ecological Environment Protection[Z].2021-08-12.

[4] Guang Fengtao, Yang Shuwang, Yi Yang. Exploration of the innovative path for the integration of ecological environment management in the Yangtze River Delta[J]. Environmental Protection, 48(20):5.

[5] Cheng Cuiyun. Discussion on the coordinated supervision mechanism of the integrated ecological environment in the Yangtze River Delta[J]. China Environment (12): 3.

[6] Wang Hui, $\mathrm{Xu}$ Lu. Don't forget your original intention to be a pioneer in law enforcement, remember your mission to protect the blue water and blue sky [N]. China Environment News, 2019-11-25 (004).

[7] Hu Shuncai, Zhang Jian. Analysis of environmental protection measures $[\mathrm{J}]$. Resource Conservation and Environmental Protection (5): 2.

[8] Zhou Jiangyan. On Green Consumption Mode and Ecological Environment Protection_-Taking the
Economic Development of Shanghai as an Example [J]. Green Technology (18): 2. 